Check for updates

Cite this: RSC Adv., 2018, 8, 33156

Received 24th July 2018

Accepted 18th September 2018

DOI: $10.1039 / c 8 r a 06247 a$

rsc.li/rsc-advances

\title{
Ag modified bismuth ferrite nanospheres as a chlorine gas sensor
}

\author{
Qiang Li, ${ }^{\star a b}$ Weiming Zhang, (D) a Chao Wang, ${ }^{a}$ Jiangwei Ma, ${ }^{a} \mathrm{Li} \mathrm{Ning}^{\mathrm{a}}$ \\ and Huiqing Fan ${ }^{\mathrm{ab}}$
}

Pure phase bismuth ferrite $\left(\mathrm{BiFeO}_{3}, \mathrm{BFO}\right)$ nanospheres were synthesized via a sol-gel method, and $\mathrm{Ag}$ was loaded on the surface of BFO by photodeposition. The effects of the Ag-modification on the morphologies and microstructural characteristics were investigated using transmission electron microscopy (TEM) and Xray powder diffraction (XRD) analyses. Only BFO peaks but no Ag peaks were observed for all samples in the XRD patterns, which is related to the small size and low loading of $\mathrm{Ag}$. The gas-sensing tests show that the response of $4 \mathrm{mg} \mathrm{AgNO}_{3}$ modified $\mathrm{BiFeO}_{3}$ (ABFO4) was 72.62 to $10 \mathrm{ppm} \mathrm{Cl}_{2}$ at $240{ }^{\circ} \mathrm{C}$, which was 2.5 times higher than that of the pristine BFO. Such outstanding gas sensing performances are attributed to the fact that the presence of Ag not only increases the density of holes and the amount of gas adsorption sites but also has a catalytic effect.

\section{Introduction}

Chlorine $\left(\mathrm{Cl}_{2}\right)$ as one of the toxic gases has been a great concern in the past few decades because it is extremely harmful to human respiratory mucosa when it is exposed to $\mathrm{Cl}_{2}$ gas at a concentration between $0.2 \mathrm{ppm}$ and $3.5 \mathrm{ppm} .{ }^{1,2}$ Meanwhile, it causes skin infections, psychological disorders, and even liver damage when combined with waste. ${ }^{3}$ Thus, it is essential to develop low cost, timely and accurate gas sensors for the detection of $\mathrm{Cl}_{2}$.

Various researchers have reported sensors using metal oxides for detection of $\mathrm{Cl}_{2}$. Guo et al. reported a one-pot solvothermal method to prepare fluorescent carbon nitride nanoparticles for detection of free chlorine. ${ }^{4}$ Miyata $e t$ al. revealed Cu-phthalocyanine thin films exhibit high sensitivity for $\mathrm{Cl}_{2} \cdot{ }^{5}$ Rao et al. reported palladium doped nickel ferrite thin films for sensing of $\mathrm{Cl}_{2}$ gas with long-term stability in spite of low sensitivity. ${ }^{6}$ As is known to all, p-type gas sensor due to its unique conduction characteristics and gas sensing mechanism, exhibits various advantages, such as low optimum operating temperature, long-term stability and low relative humidity.

It was reported that $\mathrm{BFO}$ exhibited excellent gas-sensing properties. ${ }^{7-9}$ Perovskite BFO, as p-type oxide semiconductors, displays more stable and reliable gas-sensing properties than binary metal oxides, such as $\mathrm{ZnO}, \mathrm{CuO}$ and $\mathrm{SnO}_{2}$, resulting from the fact that the ternary oxides consists of two differently sized cations. ${ }^{10,11}$ At the same time, BFO possesses distinctive surface

${ }^{a}$ School of Materials Science and Engineering, Northwestern Polytechnical University, Xi'an 710072, China. E-mail: jerrylee57318@hotmail.com; Fax: +86-29-88492642; Tel: $+86-29-88494463$

${ }^{b}$ State Key Laboratory of Solidification Processing, Xi'an 710072, China reactivity, oxygen adsorption and relatively narrow band gap $(2.19 \mathrm{eV})$ which are advantageous for enhancing gas selectivity, decreasing the humidity dependence of sensor signals to negligible levels, being conducive to transportation of valence electrons and improving recovery speed. ${ }^{12,13}$ They are especially meaningful for detection of $\mathrm{Cl}_{2}$, but the researches about BFO in the field of gas-sensing area are still limited due to its low sensitivity. The gas response of p-type oxide semiconductors could be improved remarkably by loading noble metals. ${ }^{14-16}$ Inspired by previous reports, we loaded $\mathrm{Ag}$ on the surface of BFO by photodeposition. Ag, as a noble metal, is well known for the catalyzing the redox reactions on the semiconductor surfaces. ${ }^{17}$ The catalytic nature of the $\mathrm{Ag}$ particles facilitate faster adsorption and desorption of the oxygen molecules $\left(\mathrm{O}_{2}\right)$ over the sensor surface and the capture electrons from substrate to reduce $\mathrm{O}_{2}$ into oxygen ions $\left(\mathrm{O}^{-}\right) \cdot{ }^{18}$ Therefore, $\mathrm{Ag}$ deposited $\mathrm{BFO}$, with high selectivity, sensitivity and stability is designed for the monitor of $\mathrm{Cl}_{2}$ in the present work.

Herein, we studied the sensing properties of BFO materials with different Ag loadings. The influences of different amounts of Ag particles modification and the gas sensing mechanism were also explored in detail.

\section{Experimental}

\subsection{Preparation and characterizations of BFO nanospheres}

Reagent grade bismuth nitrate pentahydrate $\left(\mathrm{Bi}\left(\mathrm{NO}_{3}\right)_{3} \cdot 5 \mathrm{H}_{2} \mathrm{O}\right)$, acetic acid $\left(\mathrm{CH}_{3} \mathrm{COOH}\right)$, iron nitrate nonahydrate $\left(\mathrm{Fe}\left(\mathrm{NO}_{3}\right)_{3} \cdot 9 \mathrm{H}_{2} \mathrm{O}\right)$, ethylene glycol $\left(\left(\mathrm{CH}_{2} \mathrm{OH}\right)_{2}\right)$ and citric acid $\left(\mathrm{C}_{6} \mathrm{H}_{8} \mathrm{O}_{7}\right)$ were used as starting materials. Perovskite-type $\mathrm{BFO}$ nanospheres were synthesized by a sol-gel method as previously reported. ${ }^{10,19,20}$ Briefly, stoichiometric $\mathrm{Bi}\left(\mathrm{NO}_{3}\right)_{3} \cdot 5 \mathrm{H}_{2} \mathrm{O}$ and $\mathrm{Fe}\left(\mathrm{NO}_{3}\right)_{3} \cdot 9 \mathrm{H}_{2} \mathrm{O}$ were dissolved in 
$\mathrm{CH}_{3} \mathrm{COOH}$ and $\left(\mathrm{CH}_{2} \mathrm{OH}\right)_{2}$, respectively. The obtained solutions were mixed after stirring for 30 minutes. $\mathrm{C}_{6} \mathrm{H}_{8} \mathrm{O}_{7}$ was added to above mixed solution after stirring at $80^{\circ} \mathrm{C}$. Then the yellow-brown sol was obtained by volatilization of the excess solvent. In order to remove the residual oxynitrides and hydrocarbon impurities, the obtained sol-gel was dried at $100{ }^{\circ} \mathrm{C}$ and preheated to $400{ }^{\circ} \mathrm{C}^{21}$ Finally, the BFO nanospheres were obtained after being calcined at $600{ }^{\circ} \mathrm{C}$ for $2 \mathrm{~h} .240 \mathrm{mg}$ BFO nanospheres were divided equally into two parts and placed in two $250 \mathrm{~mL}$ beakers, respectively. Then $80 \mathrm{~mL}$ deionized water was added into the two beakers with ultrasound for $30 \mathrm{~min}$, following by adding $0.4 \mathrm{~mL}\left(\mathrm{CH}_{2} \mathrm{OH}\right)_{2}$ solution $(5 \mathrm{wt} \%)$ and stirring for $10 \mathrm{~min}$, respectively. After that, the two beakers were added with $4 \mathrm{~mL}$ and $8 \mathrm{~mL} \mathrm{AgNO}_{3}$ solution $\left(1 \mathrm{mg} \mathrm{mL}^{-1}\right)$ and stirred for $1.5 \mathrm{~h}$. Furthermore, two solutions obtained were irradiated under a high-pressure mercury lamp $(8 \mathrm{~W})$ for $3 \mathrm{~h}$, respectively. After being washed with deionized water and absolute ethanol for several times and dried at $60{ }^{\circ} \mathrm{C}$ for $12 \mathrm{~h}$, the $\mathrm{BFO}$ nanospheres with different concentration of $\mathrm{Ag}$ were prepared ( $\mathrm{ABFO} 4$ and $\mathrm{ABFO} 8$, respectively).

The crystal structure of the as-prepared samples was analyzed via powder X-ray diffraction (XRD; D8 Advance, Bruker, Germany) at $20-70^{\circ}$ using $\mathrm{Cu}-\mathrm{K} \alpha$ radiation $(=1.5406 \AA)$. The surface morphologies of obtained products were examined using field scanned electronic microscopy (FE-SEM; JSM-6710F, JEOL, Tokyo, Japan). The chemical state was examined by highresolution X-ray photoelectron spectroscopy (XPS; VG ESCALAB220i-XL, Thermo-Scientific, Surrey, UK) with a focused monochromatized $\mathrm{Al} \mathrm{K} \alpha$ radiation $(E=1486.6 \mathrm{eV})$.

\subsection{Fabrication of gas sensors}

The process for fabrication of gas sensors was mainly as follows: a certain amount of the as-prepared samples and terpineol were mixed and ground for 1 or 2 min until a slightly sticky paste was obtained. Then the alumina ceramic tubes were coated evenly with the paste and sintered at $350{ }^{\circ} \mathrm{C}$ for $2.5 \mathrm{~h}$. After pressurizing aging, the sensitivity of the samples could be investigated.

\section{Results and discussion}

\subsection{Crystalline structure and morphology}

Fig. 1 shows the XRD patterns for pure BFO, ABFO4 and ABFO8 samples. It indicates that the BFO nanospheres exhibit pure tripartite perovskite structure with space group $R 3 c$. No secondary impurity phases are detected. The high diffraction peaks reveal the high crystallinity of the as-prepared samples. The diffraction peaks of the nanospheres was largely weakened with the increased loading amount of $\mathrm{Ag}$ particles. Compared with pure BFO, the intensities of peaks for (012) and (104) of ABFO4 and ABFO8 decrease significantly: 57\%, 39\% and $72 \%$, $61 \%$, respectively. This can be explained that the loading of $\mathrm{Ag}$ causes the X-rays to scatter, resulting in the signal to weaken.

The morphology of the samples is confirmed by SEM and the results are shown in Fig. 2(a-c). The pure BFO consists of agglomerated nanospheres with diameters ranging from 50$70 \mathrm{~nm}$ in Fig. 2(a), ${ }^{22}$ which is in line with the reported in the literature. ${ }^{19-21}$ The SEM images [Fig. 2(b)] of the ABFO4 clearly depicts relatively broadened nanosphere distribution,

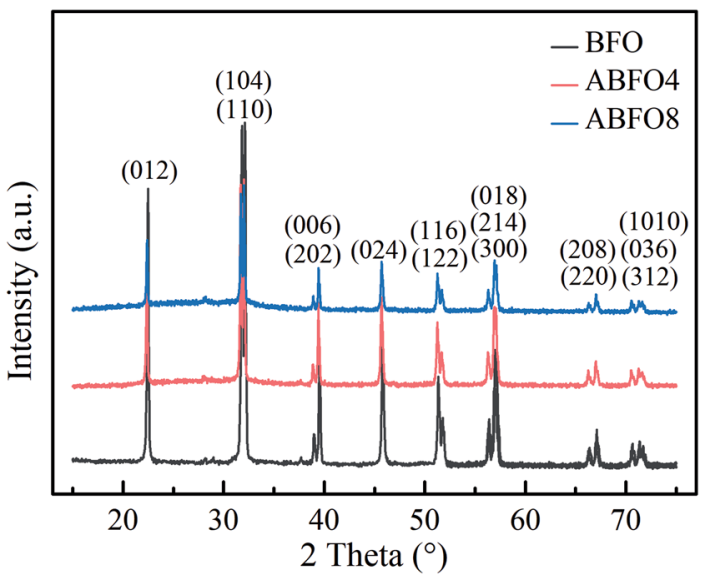

Fig. 1 The XRD patterns of pure BFO, ABFO4 and ABFO 8 samples

approximately 40-70 $\mathrm{nm}$ and the ABFO8 [Fig. 2(c)] displays a totally inhomogeneous particle size distribution (30-120 $\mathrm{nm}){ }^{23}$ No changes can be found in the surface morphology of BFO by SEM after Ag loading. All results indicate that the loading of $\mathrm{Ag}$, small in size and uniform dispersion, has a certain influence on the size of BFO.

XPS is carried out to verify the existence of $\mathrm{Ag}$ and explore the effects of $\mathrm{Ag}$ modification on the chemical state of BFO. The spectra are displayed in Fig. 3. Peaks of $\mathrm{Bi}, \mathrm{Fe}, \mathrm{O}, \mathrm{Ag}$ and $\mathrm{C}$ elements are observed in the fully scanned spectrum of ABFO4. The appearance of $\mathrm{Ag} 3 \mathrm{~d}_{3 / 2}$ and $\mathrm{Ag} 3 \mathrm{~d}_{5 / 2}$ peaks indicates that the $\mathrm{Ag}$ nanoparticles are successfully deposited on the surface of BFO nanospheres by light irradiation. Fig. 3(b) displays $\mathrm{Ag}$ 3d XPS spectrum of ABFO4 and $\mathrm{O}$ 1s (inset) spectra of BFO and ABFO4. As seen from Fig. 3(b), the $\mathrm{O}$ 1s has two peaks at $533.0 \mathrm{eV}$ and $535.6 \mathrm{eV}$, respectively. The peak with a lower binding energy is related to the $\mathrm{O} 1 \mathrm{~s}$ binding energy whereas the other is attributed to the loss of oxygen in the sample. ${ }^{24-26}$ But for $\mathrm{ABFO}$, the peak located at $533.0 \mathrm{eV}$ decreases dramatically. This means that the change in the content of the oxygen atom
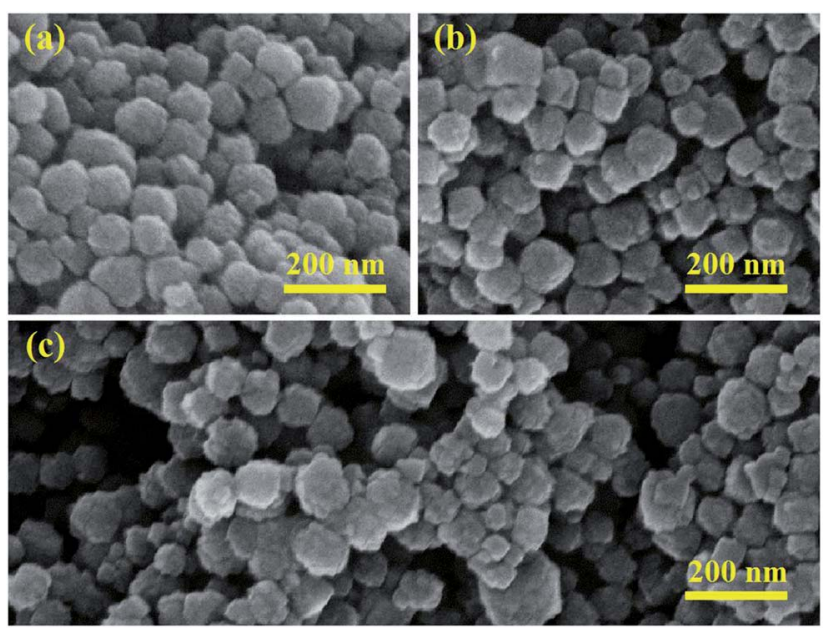

Fig. 2 The SEM images of (a) pure BFO, (b) ABFO4, (c) ABFO8. 
(a)

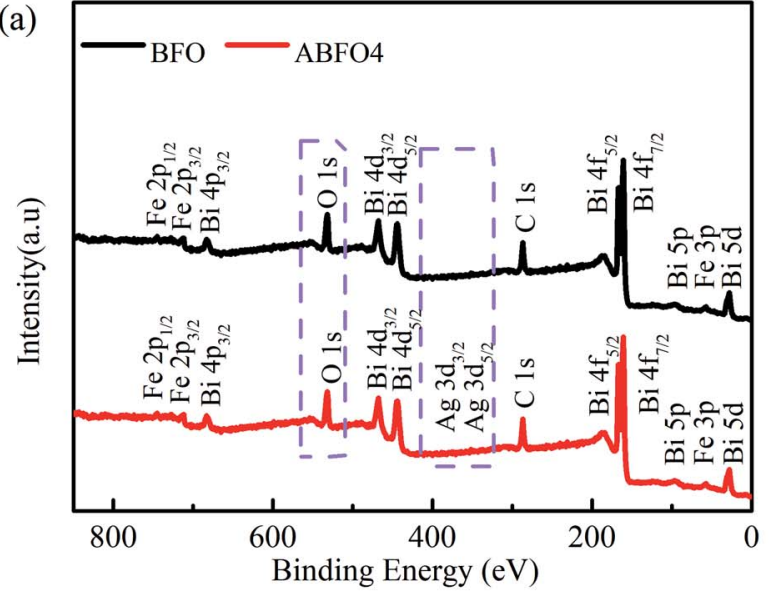

(b)

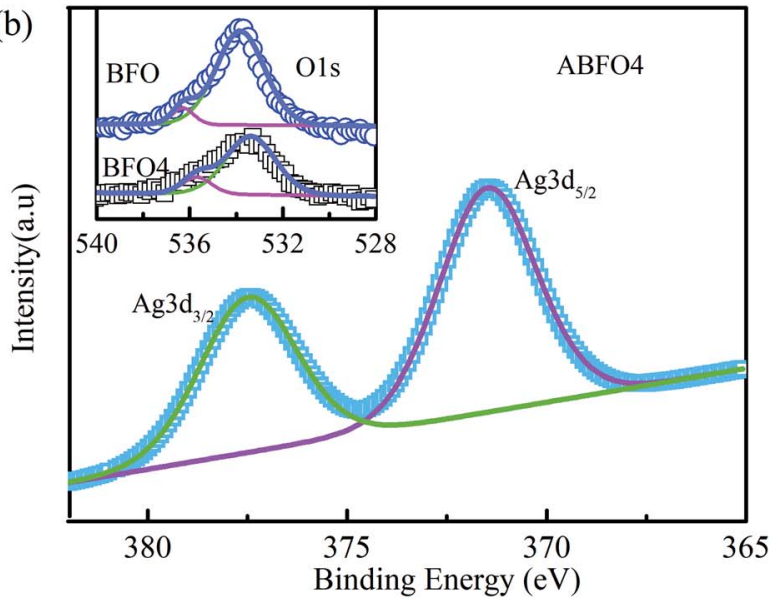

Fig. 3 XPS spectra of pure BFO nanospheres and ABFO4 samples: (a) fully scanned spectra, (b) $O 1 \mathrm{~s}$ and $\mathrm{Ag} 3 \mathrm{~d}_{3 / 2}, \mathrm{Ag} 3 \mathrm{~d}_{5 / 2}$.

sharply while the peak at $535.6 \mathrm{eV}$ is almost constant, indicating that the oxygen vacancy does not change significantly. From the illustration of Fig. 3(b), it is found that the difference in the binding energy between the $\mathrm{Ag} 3 \mathrm{~d}_{3 / 2}$ and $3 \mathrm{~d}_{5 / 2}$ states is about $6.3 \mathrm{eV}$, which differs from that of $\mathrm{Ag}_{2} \mathrm{O}$ and $\mathrm{AgO}$. Therefore, the XPS results demonstrate that Ag exists as metallic phase, but it cannot be examined by the XRD and SEM, which may be interpreted that $\mathrm{Ag}$ particles are low content, small in size and uniform dispersion.

\subsection{Gas sensing properties}

Generally, the absorption of the target gas can be much faster at higher temperatures, when the contaminant adsorption may be restricted. Therefore, the sensitivity and stability can be enhanced to a large extent. ${ }^{27}$ Nevertheless, extremely high temperatures can change the composition and structure of the sensor materials. Hence, parallel experiments are performed from $200{ }^{\circ} \mathrm{C}$ to $300{ }^{\circ} \mathrm{C}$ to optimize the working temperature of the gas sensors which are exposed to $\mathrm{Cl}_{2}$ gas at a concentration (a)

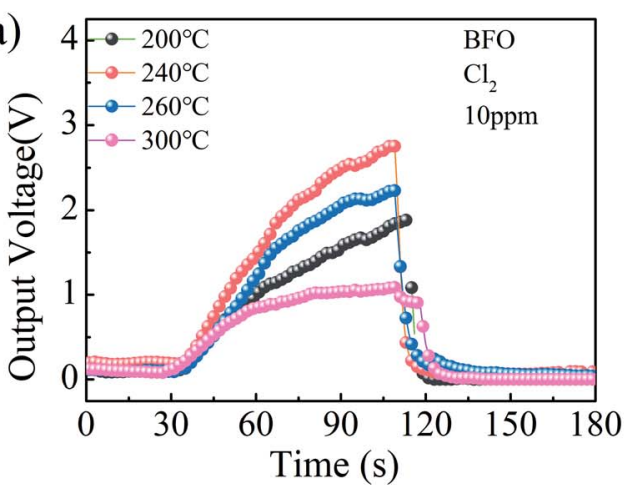

(c)

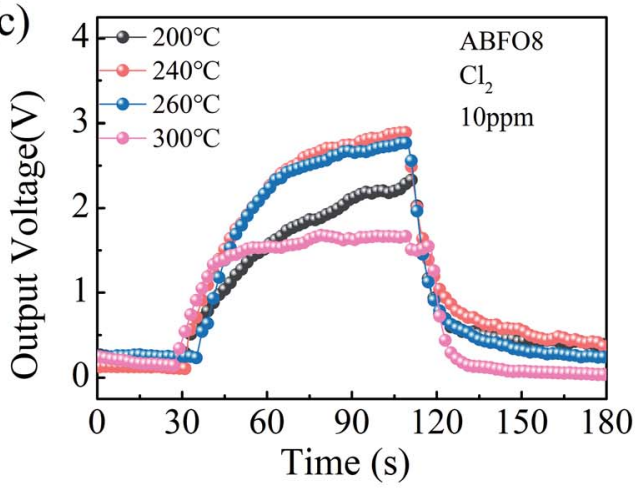

(b)

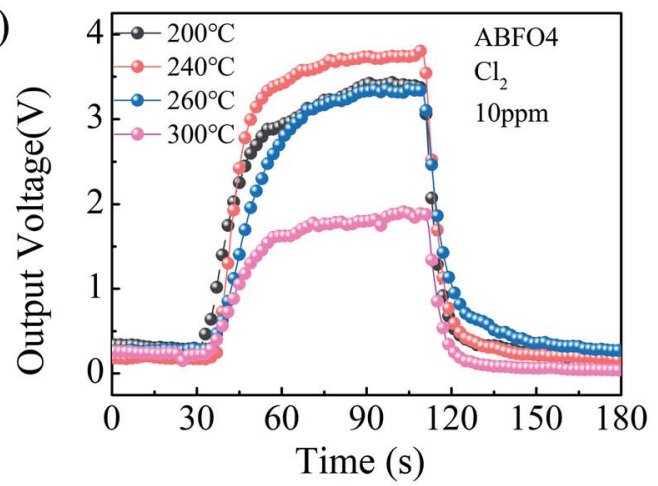

(d)

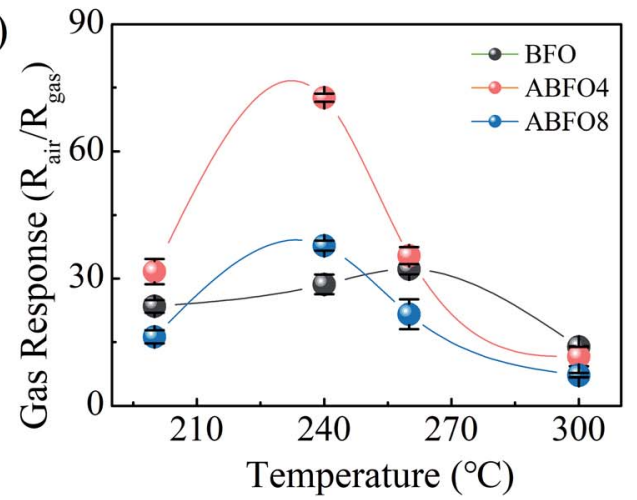

Fig. 4 Typical response and recovery curve of (a) BFO, (b) ABFO4 and (c) ABFO8, respectively, exposed to 10 ppm $\mathrm{Cl}_{2}$ at different working temperatures; (d) typical response and recovery curve of sensors and the sensitivity pattern of BFO, ABFO4 and ABFO8, respectively exposed to $10 \mathrm{ppm} \mathrm{Cl} \mathrm{Cl}_{2}$ at $240{ }^{\circ} \mathrm{C}$. 
(a)

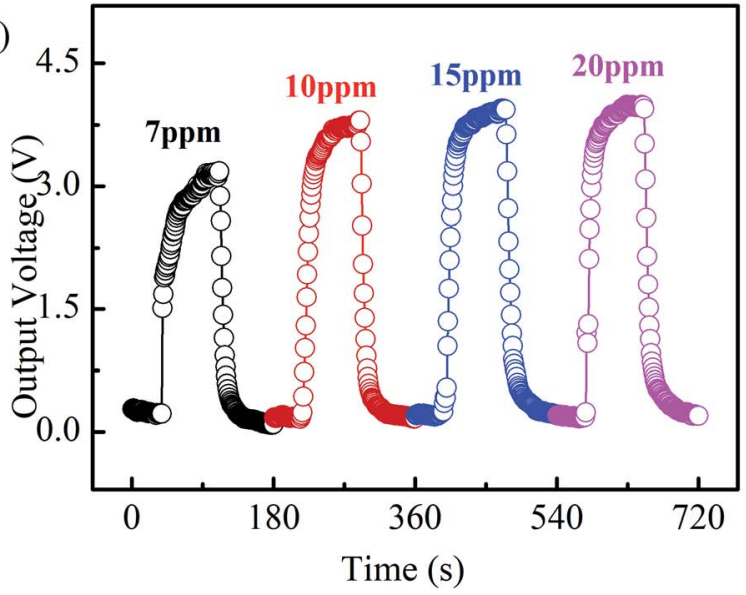

(b)

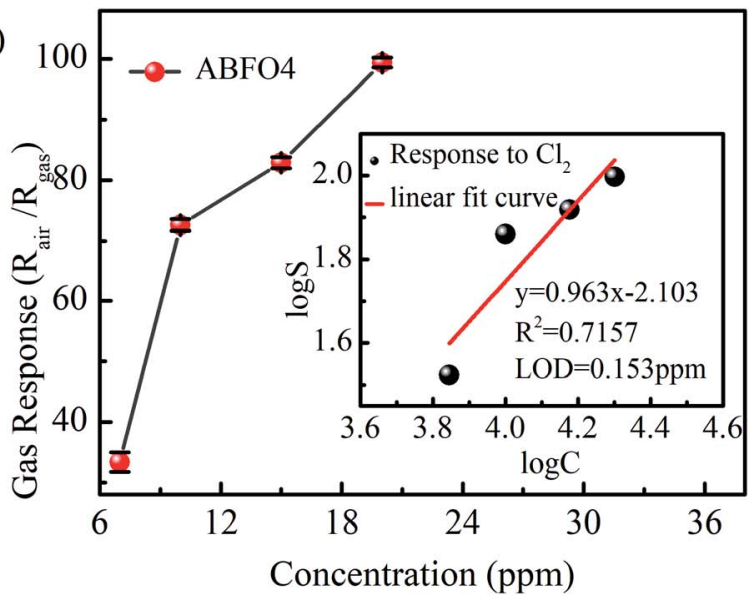

Fig. 5 (a) Typical response and recovery curve of sensors and (b) sensitivity pattern of ABFO4 to $\mathrm{Cl}_{2}$ as the concentration varied from 7 ppm to $20 \mathrm{ppm}$ at $240^{\circ} \mathrm{C}$.

Table 1 Comparison of the chlorine sensing performance of various kinds of semiconductor gas sensors

\begin{tabular}{|c|c|c|c|c|c|}
\hline Sensing materials & $\begin{array}{l}\text { Working } \\
\text { temperature }\left({ }^{\circ} \mathrm{C}\right)\end{array}$ & Response $\left(R_{\mathrm{a}} / R_{\mathrm{g}}\right)$ & $\begin{array}{l}\text { Detection } \\
\text { concentration (ppm) }\end{array}$ & $\begin{array}{l}\text { Response/ } \\
\text { recovery time (s) }\end{array}$ & Ref. \\
\hline $\mathrm{NiO}$ & 200 & 0.21 & 10 & $12 / 27$ & 3 \\
\hline $\mathrm{MgO}-\mathrm{In}_{2} \mathrm{O}_{3}$ & 275 & 3.2 & 7 & - & 30 \\
\hline $\mathrm{SnO}_{2}$ & 260 & 26.8 & 5 & $21 / 17$ & 31 \\
\hline $\operatorname{In}_{2} \mathrm{O}_{3}$ & 300 & 26.1 & 5 & $2 / 4$ & 32 \\
\hline
\end{tabular}

of $10 \mathrm{ppm}$. The response and recovery curves of sensors at different temperature are shown in Fig. 4.

The resistance of semiconductor metal oxide gas sensors decreases when exposed to oxide gases, indicating a p-type conduction mechanism. ${ }^{28}$ It is noted that the conduction of the BFO is dominated by the hole concentration. The gas response increases along with the operating temperature and reaches a maximal value at $240{ }^{\circ} \mathrm{C}$, after declines when further raising the temperature as shown in Fig. 4(a). This phenomenon is also observed in Fig. 4(b) and (c). It means that the optimum operating temperature for BFO and $\mathrm{Ag}$ decorated BFO sensors is $240{ }^{\circ} \mathrm{C}$. Fig. 4 (d) displays that the gas response of

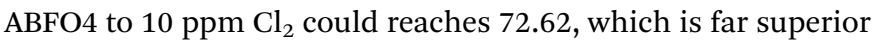
to pure BFO and ABFO8. The gas response of p-type gas sensors for oxidizing gases was calculated from the following eqn (1):

$$
S=R_{\mathrm{a}} / R_{\mathrm{g}}
$$

where $S$ represents sensitivity, $R_{\mathrm{a}}$ and $R_{\mathrm{g}}$ are the stabilized resistances of the sensor material in presence of air $\left(R_{\mathrm{a}}=(5-\right.$ $\left.\left.V_{(\text {air })}\right) /\left(V_{(\text {air })} / R_{\mathrm{L}}\right)\right)$ and target gas $\left(R_{\mathrm{g}}=\left(5-V_{(\text {gas })}\right) /\left(V_{(\text {gas })} / R_{\mathrm{L}}\right)\right), V_{(\text {air })}$ and $V_{\text {(gas) }}$ represent resistor $R_{\mathrm{L}}$ output voltage in air and measured gas, respectively.

Sensitivity is the most crucial factor when determining whether a gas sensor is suitable for practical application. Fig. 5 shows the typical response/recovery curves of sensors and gas response of $\mathrm{ABFO} 4$ to $\mathrm{Cl}_{2}$ as the concentration varied from
$7 \mathrm{ppm}$ to $20 \mathrm{ppm}$ at $240{ }^{\circ} \mathrm{C}$. The output voltage of the sensors increases with increasing of the concentration of target gas (720 ppm) in Fig. 5(a). Fig. 5(b) shows that the gas response value rises rapidly from $7 \mathrm{ppm}$ to $10 \mathrm{ppm}$ while this trend is suppressed when the concentration of target gas further goes up. It is also noteworthy that the limit of detection (LOD) of ABFO4 sensor (inset) for $\mathrm{Cl}_{2}$ is $0.153 \mathrm{ppm}$. The sensitivity comparison of ABFO4 nanospheres and other reported materials in $\mathrm{Cl}_{2}$ at the optimum working temperature are summarized in Table

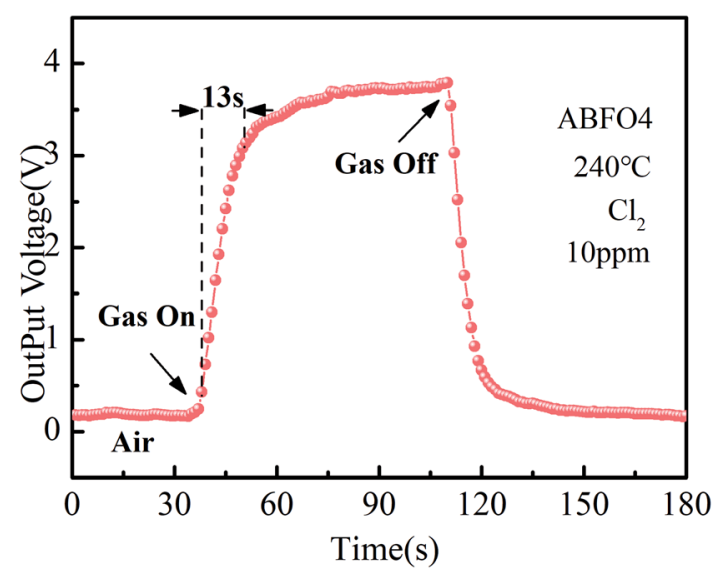

Fig. 6 The response time of $\mathrm{ABFO} 4$ exposed to $10 \mathrm{ppm} \mathrm{Cl}_{2}$ at $240^{\circ} \mathrm{C}$. 

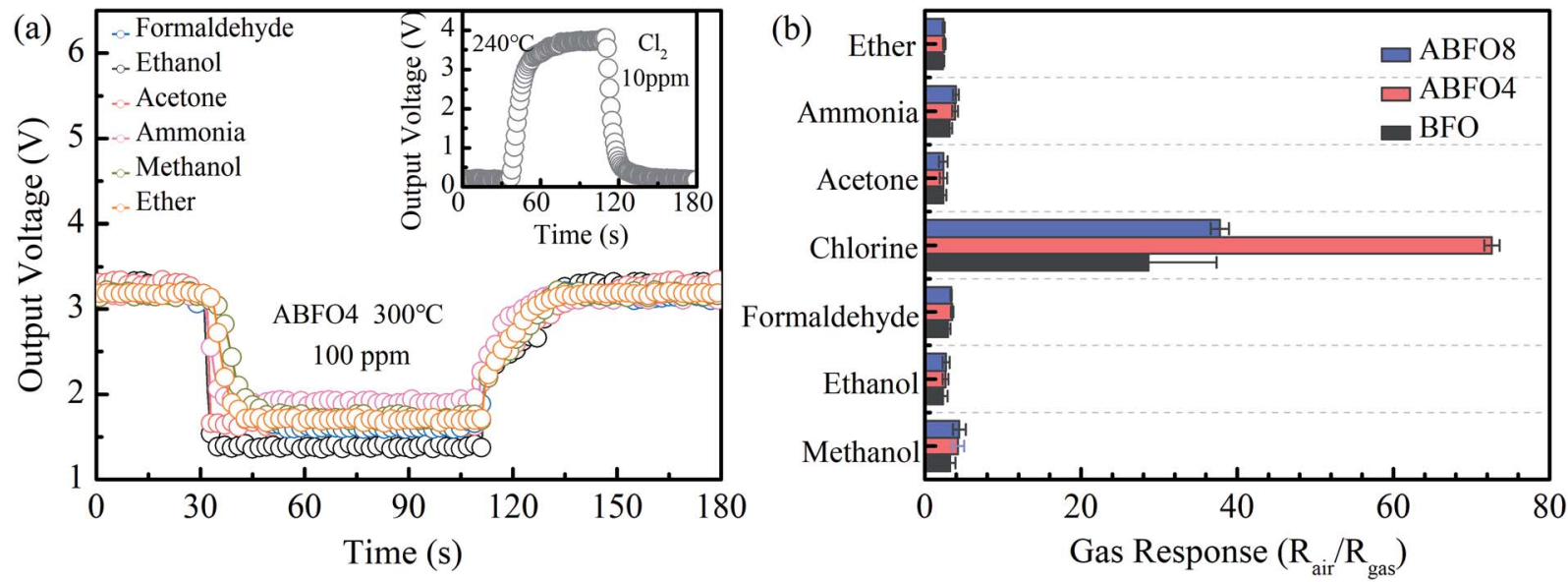

Fig. 7 (a) Typical response and recovery curve for different gases of ABFO4; (b) the sensitivity pattern of BFO, ABFO4 and ABFO8, respectively, exposed to different gases ( $100 \mathrm{ppm}$ methanol, ethanol, formaldehyde, acetone and ether at $300{ }^{\circ} \mathrm{C}$ but $10 \mathrm{ppm} \mathrm{Cl}_{2}$ at $240{ }^{\circ} \mathrm{C}$ ).

1.,29-32 Compared to p-type semiconductor metal oxides, the response time is shorter.

Fig. 6 shows the response and recovery curve of ABFO4 sensor to $10 \mathrm{ppm} \mathrm{Cl}_{2}$ at $240{ }^{\circ} \mathrm{C}$. The gas response time is $24 \mathrm{~s}$. Compared with many metal oxides, such as $\mathrm{In}_{2} \mathrm{O}_{3}$, BFO displays a long response time, which is related to the p-type semiconductor response mechanism of oxidizing gases. But the stability of BFO is much higher in long term application and extreme conditions, so it still has a broad development prospects and practical value.

Selectivity is another vital factors in the development of gas sensors for the real market. BFO exhibits a high performance to ethanol at $300{ }^{\circ} \mathrm{C}$ according to the previous paper. Fig. 7(a) shows a typical response curve of ABFO4 to $100 \mathrm{ppm}$ ammonia, acetone, ethanol, ether, formaldehyde and methanol at $300^{\circ} \mathrm{C}$, but $10 \mathrm{ppm} \mathrm{Cl}_{2}$ at $240{ }^{\circ} \mathrm{C}$ (inset). The gas response of $\mathrm{BFO}$, $\mathrm{ABFO} 4$ and $\mathrm{ABFO} 8$ to $10 \mathrm{ppm} \mathrm{Cl}_{2}$ and $100 \mathrm{ppm}$ other gases is displayed in Fig. 7(b). As is shown, the BFO material has excellent selectivity for $\mathrm{Cl}_{2}$.

\subsection{Gas sensing mechanism}

To get a better understanding of the BFO mechanism for $\mathrm{Cl}_{2}$, it can be analyzed from the following aspects: chemisorption, a hole-accumulation layer, band bending and resistance change. The dangling bonds are a vital precondition for gas sensors, because it can possess geometrically and electronically favorable sites for molecule chemisorption and charge transfer in gas-solid interface. ${ }^{33}$ The adsorption of chlorine and oxygen can be figured out by the reactions as follows:

$$
\begin{gathered}
2 \mathrm{~S}+\mathrm{O}_{2} \rightarrow \mathrm{O}_{(\mathrm{ads})}+\mathrm{O}_{(\mathrm{ads})} \\
2 \mathrm{~S}+\mathrm{Cl}_{2} \rightarrow \mathrm{Cl}_{(\mathrm{ads})}+\mathrm{Cl}_{(\mathrm{ads})} \\
\left(\mathrm{V}_{\mathrm{O}}^{\prime}\right)_{(\text {surf })}+0.5 \mathrm{O}_{2} \rightarrow \mathrm{O}_{\mathrm{o}(\mathrm{ads})}^{\times}+2 \mathrm{~h}^{+}
\end{gathered}
$$

where $\mathrm{S}, \mathrm{V}_{\mathrm{O}}^{\prime}, \mathrm{O}_{\mathrm{o}}^{\times}$denotes the adsorption sites on the surface, oxygen vacancy and lattice oxygen, respectively.
On the surface of the semiconductor, electrons are drawn by $\mathrm{O}_{2}$ from the conduction band of the materials and trapped at the surface to form ionized oxygen. According to the Wolkenstein's model, ${ }^{34-36}$ the adsorbed $\mathrm{O}_{2}$ are partially ionized into different chemical forms $\left(\mathrm{O}^{2-}, \mathrm{O}^{-}\right.$or $\mathrm{O}^{2-}$, etc. $)$ at different temperatures. The process of semiconductor surface resistance change is mainly dominated by the process of $\mathrm{O}_{2}$ and chlorine molecules adsorption, ionization and desorption.

The mechanism for the response of BFO nanospheres to $\mathrm{Cl}_{2}$ is shown in Fig. 8. In the air atmosphere, $\mathrm{O}_{2}$ are adsorbed on the surface of BFO nanospheres and $\mathrm{O}_{2}^{-}$ions are formed at 100$300{ }^{\circ} \mathrm{C}$, as the eqn (5) shows. When $\mathrm{Cl}_{2}$ is injected, the reactions in eqn (6)-(9) occur. Electrons are captured by $\mathrm{Cl}_{2}$ as shown in eqn (6) and (7), resulting in an increase in the number of holes. $\mathrm{O}_{2}^{-}$ions are consumed by $\mathrm{Cl}_{2}$ as displayed in eqn (8). In stark contrast, electrons are released (eqn (9)), resulting in a decrease in the number of holes due to the partial electron-hole neutralization. As a result, the reactions in eqn (6)-(8) decrease the resistance of p-type metal oxide semiconductors, whereas the reaction in eqn (9) increase the resistance..$^{37}$ In this work, the resistance of $\mathrm{BFO}, \mathrm{ABFO} 4$ and $\mathrm{ABFO} 8$ sensors decreased among all $\mathrm{Cl}_{2}$ concentrations at all measured temperatures. Thus, the sensing mechanism is dominated as eqn (6)-(8) demonstrate. Meanwhile, the reactions in eqn (6)-(8) reduce the amount of

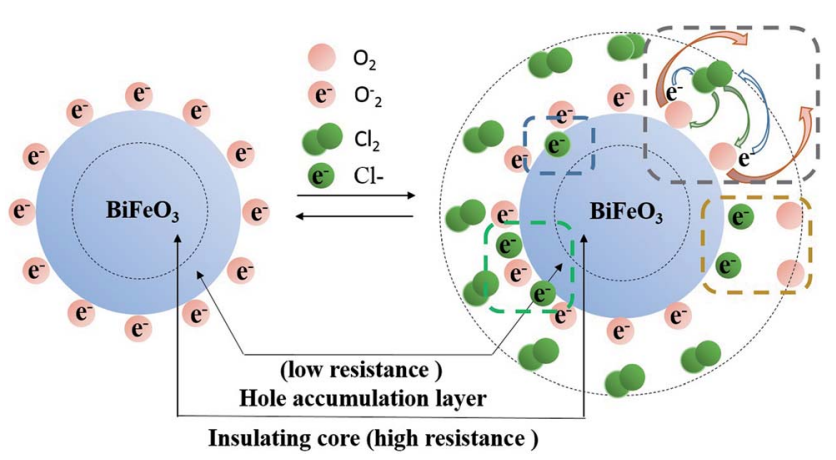

Fig. $8 \mathrm{Cl}_{2}$ sensing mechanism of BFO nanospheres. 
(a)

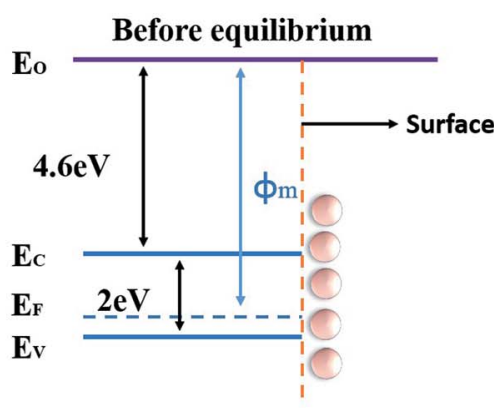

(b)

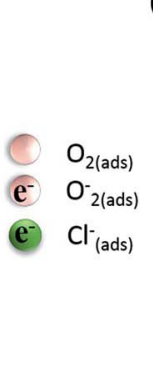

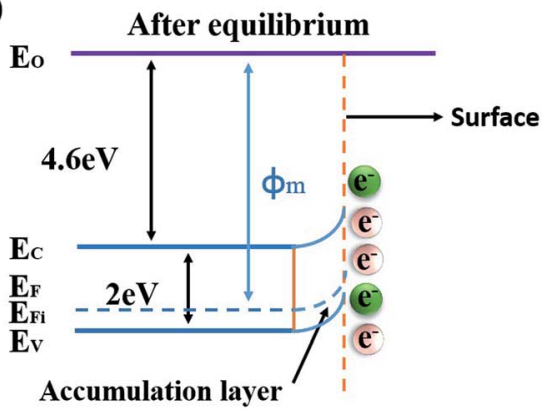

Fig. 9 Energy band structure of BFO (a) before equilibrium, (b) after equilibrium.

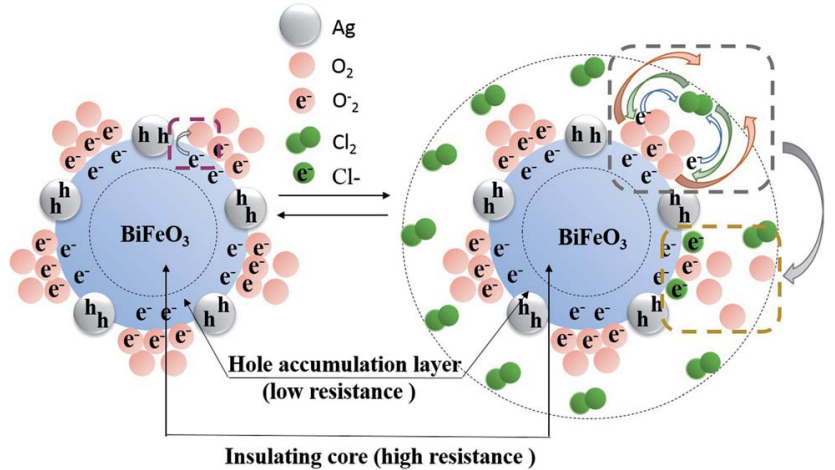

Fig. $10 \mathrm{Cl}_{2}$ sensing mechanism of $\mathrm{Ag}$ particles decorated BFO nanospheres.

electrons on the surface and form a hole accumulation layer near the surface, causing the valence band to bend upwards and form a potential barrier that hinders the reaction, as shown in Fig. 9.

$$
\begin{gathered}
\mathrm{O}_{2(\text { ads })}+\mathrm{e}^{-} \rightarrow \mathrm{O}_{2(\text { ads })}{ }^{-} \\
\mathrm{Cl}_{2}+2 \mathrm{e}^{-} \rightleftharpoons 2 \mathrm{Cl}_{(\text {surf })}{ }^{-} \\
\mathrm{Cl}_{2}+2\left(\mathrm{~V}_{\mathrm{O}}^{\prime}\right)_{(\text {(surf) }}+2 \mathrm{e}^{-} \rightleftharpoons 2\left(\mathrm{Cl}_{\mathrm{o}}^{-}\right)_{(\text {(surf })} \\
\mathrm{Cl}_{2}+\left(2 \mathrm{O}_{2}^{-}\right)_{(\text {ads })} \rightleftharpoons 2 \mathrm{Cl}_{(\text {ads })}+2 \mathrm{O}_{2}
\end{gathered}
$$

$$
\mathrm{Cl}_{2}+2 \mathrm{O}_{\mathrm{o}(\mathrm{ads})}^{\times} \rightleftharpoons 2 \mathrm{Cl}_{\mathrm{o}(\mathrm{ads})}^{-}+2 \mathrm{O}_{2}+2 \mathrm{e}_{(\mathrm{bulk})}
$$

The gas sensing mechanism of $\mathrm{Cl}_{2}$ by $\mathrm{Ag}$ nanoparticles modified BFO nanospheres is shown in Fig. 10. Fig. 11 shows the band structure and holes transfer after Ag nanoparticles loading. The main reasons for the promotion of gas sensitivity of BFO by Ag nanoparticles are as follows: as a p-type semiconductor, the majority carriers in the BFO nanospheres are holes. When Ag is loaded on the BFO surface, the number of positive charges on the BFO nanospheres decreases and the conduction band and the valence band bends downward because the holes on BFO nanospheres transfer to Ag. ${ }^{38}$ Energy potential is generated between the Ag and BFO nanospheres barrier. With the separation of electrons and holes, electrons are more likely to combine with $\mathrm{O}_{2}$ and $\mathrm{Cl}_{2}$ on the surface, and no barrier is generated due to the decreased amount of electrons in the conduction band, which promotes the progress of the reaction. At the same time, the Fermi levels of BFO and Ag match each other to the same level after the contact, since the work function $\varphi_{\mathrm{m}}$ of BFO is lower than the work function $\varphi_{\mathrm{s}}$ of Ag.

Ag particles can also serve as a special adsorption site for $\mathrm{O}_{2}$ and $\mathrm{Cl}_{2}$; in addition, a Schottky junction can be formed at the interface of $\mathrm{Ag}$ and $\mathrm{BFO}$, thereby reducing the intergranular barriers and improving the interfacial effect; ${ }^{39,40}$ furthermore, due to the fast transfer of charge carriers from $\mathrm{BFO}$ to the $\mathrm{Ag}$,
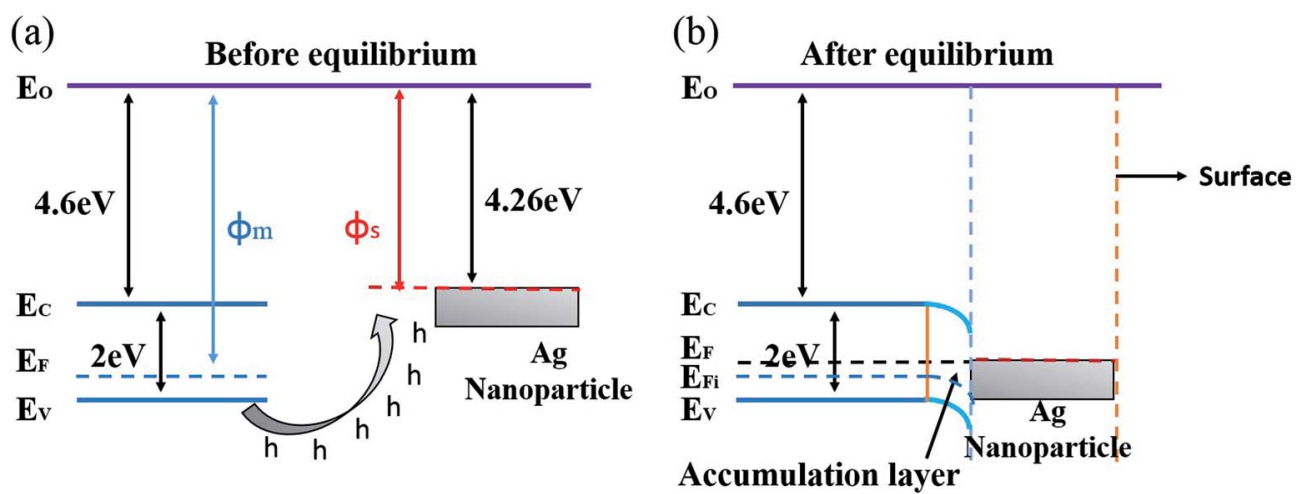

Fig. 11 Energy band structure and hole transfer in Ag nanoparticles decorated BFO microspheres (a) before equilibrium, (b) after equilibrium. 
the number of electrons for reactions sites is increased and the reaction can be rapidly saturated. Thereby, the gas response is largely enhanced and the response time is shortened.

Hence, it is noteworthy that the above-mentioned results can account for the improvement in the sensitivity of BFO, with a certain amount of $\mathrm{Ag}$ decoration (ABFO4). However, when an overdose of $\mathrm{Ag}$ is loaded (ABFO8), the adsorbed oxygen goes down significantly, resulting in reduction of the amount of oxygen and chlorine gas adsorption, thus decreasing the gas response.

\section{Conclusions}

We successfully fabricated $\mathrm{Ag}$ modified BFO sensors for $\mathrm{Cl}_{2}$ sensing application. The phase composition, surface morphology and element chemical state of $\mathrm{Ag}$ modified $\mathrm{BiFeO}_{3}$ nanospheres were studied systematically. The $\mathrm{Cl}_{2}$ gas sensing characteristics of the sensors were also investigated detailedly. Compared with $\mathrm{BFO}$ and $\mathrm{ABFO} 8, \mathrm{ABFO} 4$ exhibited a superior sensitivity for $\mathrm{Cl}_{2}$ with rapid response $(13 \mathrm{~s})$ and relatively short recovery time (24 s) to $10 \mathrm{ppm} \mathrm{Cl}_{2}$ at $240{ }^{\circ} \mathrm{C}$. Furthermore, the as-prepared $\mathrm{ABFO} 4$ sensor showed excellent selectivity in natural environment. The largely enhanced sensing performances are attributed to the fact that the presence of $\mathrm{Ag}$ not only increase the density of holes and the amount of gas adsorption sites but also has a catalytic effect. Thus, the modification of the noble metal opens up a new direction for the improvement of the gas sensitivity of p-type semiconductors to $\mathrm{Cl}_{2}$.

\section{Conflicts of interest}

There are no conflicts to declare.

\section{Acknowledgements}

This work is supported by the National Nature Science Foundation (51672220), the SPDRF (20116102130002), the 111 Program (B08040) of MOE, the National Defense Science Foundation (32102060303), the Xi'an Science and Technology Foundation (XBCL-1-08, CXY1706-5), the SKLP Foundation (KP201421, KP201523), the Project of Key Areas of Innovation team in Shaanxi Province (2014KCT-12), the Fundamental Research Funds for the Central Universities (3102014JGL01002). The Shaanxi Provincial Science Foundation (2017KW-018), and the NPU Gaofeng Project (17GH020824) of China.

\section{References}

1 C. Winder, Environ. Res., 2001, 85, 105-114.

2 C. White and J. Martin, Proc. Am. Thorac. Soc., 2010, 7, 257263.

3 M. Arif, A. Sanger and A. Singh, J. Electron. Mater., 2018, 47, 3451-3458.

4 J. Guo, Y. Lin, H. Huang, S. Zhang, T. Huang and W. Weng, Sens. Actuators, B, 2017, 224, 965-971.
5 T. Miyata, S. Kawaguchi and M. Ishii, Thin Solid Films, 2003, 425, 255-259.

6 P. Rao and R. V. Godbole, J. Magn. Magn. Mater., 2016, 405, 219-224.

7 S. Waghmare, V. Jadhav, S. Gore, S. Yoon, S. Ambade, B. Lokhande, R. Mane and S. Han, Mater. Res. Bull., 2012, 47, 4169-4173.

8 X. Yu, Y. Wang, Y. Hu, C. Cao and H. Chan, J. Am. Ceram. Soc., 2009, 92, 3105-3107.

9 S. Waghmare, V. Jadhav, S. Shaikh, R. Mane, J. Rhee and C. O'Dwyer, Sens. Actuators, A, 2018, 271, 37-43.

10 G. Dong, H. Tian and J. Fang, RSC Adv., 2015, 5, 2961829623.

11 H. Obayashi, Y. Sakurai and T. Gejo, J. Solid State Chem., 1976, 17, 299-303.

12 H. Kim and J. Lee, Sens. Actuators, B, 2014, 192, 607-627.

13 X. Deng, C. Song, Y. Tong, G. Yuan, F. Gao, D. Liu and S. Zhang, Phys. Chem. Chem. Phys., 2018, 20, 3648-3657.

14 E. Gaspera, M. Guglielmi, A. Martucci, L. Giancaterini and C. Cantalini, Sens. Actuators, B, 2012, 164, 54-63.

15 J. Fu, C. Zhao, J. Zhang, Y. Peng and E. Xie, ACS Appl. Mater. Interfaces, 2013, 5, 7410-7416.

16 N. G. Cho, H.-S. Woo, J.-H. Lee and I.-D. Kim, Chem. Commun., 2011, 47, 11300-11302.

17 R. Joshi and F. Kruis, Appl. Phys. Lett., 2006, 89, 153116.

18 W. Wei, S. Guo, C. Chen, L. Sun, Y. Chen, W. Guo and S. Ruan, J. Alloys Compd., 2017, 695, 1122-1127.

19 H. Wu, P. Xue, Y. Lu and X. Zhu, J. Alloys Compd., 2017, 731, 471-477.

20 T. Park, G. Papaefthymiou, A. Viescas, A. Moodenbaugh and S. Wong, Nano Lett., 2007, 7, 766-772.

21 X. Ren, Y. Zhao, Z. Liu and H. Fan, ACS Appl. Mater. Interfaces, 2016, 8, 26190-26197.

22 M. Hjiri, L. ElMir, S. Leonardi, A. Pistone, L. Mavilia and G. Neri, Sens. Actuators, B, 2014, 196, 413-420.

23 T. Dang, N. Hoa, N. Duy and N. Hieu, ACS Appl. Mater. Interfaces, 2016, 8, 4828-4837.

24 L. Fang, J. Liu, S. Ju, F. Zheng, W. Dong and M. Shen, Appl. Phys. Lett., 2010, 97, 242501-242503.

25 C. Rath, P. Mohanty, A. Pandey and N. Mishra, J. Phys. D: Appl. Phys., 2009, 42, 205101.

26 M. Naeem, S. Hasanain, M. Kobayashi, Y. Ishida, A. Fujimori, S. Buzby and S. Shah, Nanotechnology, 2006, 17, 2675-2680.

27 K. Toda, Bunseki Kagaku, 1990, 39, 611-615.

28 D. Williams, Sens. Actuators, B, 1999, 57, 1-16.

29 C. Reddy, S. Manorama and V. Rao, Sens. Actuators, B, 1999, 55, 90-95.

30 T. Miyata, T. Hikosaka and T. Minami, Sens. Actuators, B, 2000, 69, 16-21.

31 D. Wang, P. Hu, J. Xu, X. Dong and Q. Pan, Sens. Actuators, B, 2009, 140, 383-389.

32 P. Li and H. Fan, Mater. Sci. Semicond. Process., 2015, 29, 8389.

33 G. Sun, P. Zhao, W. Zhang, H. Li and C. He, Mater. Chem. Phys., 2017, 186, 305-311. 
34 A. Labidi, E. Gillet, R. Delamare, M. Maaref and K. Aguir, Sens. Actuators, B, 2006, 120, 338-345.

35 K. Wetchakun, T. Samerjai, N. Tamaekong, C. Liewhiran, C. Siriwong, V. Kruefu, A. Wisitsoraat, A. Tuantranont and S. Phanichphant, Sens. Actuators, B, 2011, 160, 580-591.

36 R. Khadayate, M. Chaudhari, S. Disawal and P. Patil, Invertis Journal of Science \& Technology, 2009, 2, 185-189.
37 A. Dey, Mater. Sci. Eng., B, 2018, 229, 206-217.

38 Y. Chen, F. Zheng, Y. Min, T. Wang, Y. Zhang and Y. Wang, J. Mater. Sci.: Mater. Electron., 2012, 23, 1592-1598.

39 L. Chen and S. Tsang, Sens. Actuators, B, 2003, 89, 68-75.

40 S. Sarkar, M. Pradhan, A. K. Sinha, M. Basu, Y. Negishi and T. Pal, Inorg. Chem., 2010, 49, 8813. 